\section{Blood pressure target goals from guidelines of 2002-2014}

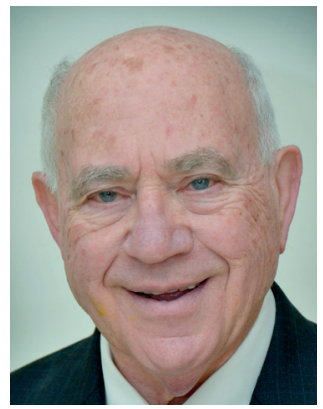

Wilbert S Aronow*

\author{
“The 2014 American Society of Hypertension/ \\ International Society of Hypertension guidelines
} recommended reducing the blood pressure to less than $140 / 90 \mathrm{mmHg}$ in patients younger than 80 years of age. These guidelines recommended lowering the blood pressure to less than $150 / 90 \mathrm{mmHg}$ in patients aged 80 years and older."
The 2003 guidelines report from the seventh report of the Joint National Committee (JNC 7) on Prevention, Detection, Evaluation, and Treatment of High Blood Pressure recommended that the target blood pressure in adults without diabetes mellitus or chronic kidney disease (CKD) be less than $140 / 90 \mathrm{mmHg}$ [1]. In the absence of randomized control data, these guidelines recommended that patients with diabetes mellitus or with CKD should have their blood pressure decreased to less than $130 / 80 \mathrm{mmHg}[1]$. In the absence of randomized control data, the American Diabetes Association 2003 guidelines recommended that diabetics with hypertension should have their blood pressure decreased to less than $130 / 80 \mathrm{mmHg}$ [2]. In the absence of randomized control data, the National Kidney Foundation Kidney Disease Outcome Quality Initiative 2002 guidelines recommended that patients with CKD and hypertension should have their blood pressure decreased to less than $130 / 80 \mathrm{mmHg}$ [3]. In the absence of randomized control data, the American Heart Association 2007 guidelines recommended that patients with hypertension at high risk for coronary events such as those with coronary artery disease, a coronary artery risk equivalent, diabetes mellitus, CKD, or a 10-year Framingham risk score $\geq 10 \%$ should have their blood pressure decreased to less than $130 / 80 \mathrm{mmHg}$ [4]. These guidelines also recommended that patients with hypertension and left ventricular dysfunction should have their blood pressure reduced to less than $120 / 80 \mathrm{mmHg}$ [4].

These guidelines needed to be updated [5]. Clinical studies that favored a blood pressure less than $140 / 90 \mathrm{mmHg}$ in patients at high risk for coronary events included the following studies [6-13].

The American College of Cardiology Foundation/American Heart Association 2011 expert consensus document on hypertension in the elderly recommended a blood pressure less than $140 / 90 \mathrm{mmHg}$ in adults younger than 80 years of age at high risk for cardiovascular events. [14]. On the basis of data from the Hypertension in the Very Elderly Trial [15], these guidelines state that the systolic blood pressure (SBP) should be reduced to $140-145 \mathrm{mmHg}$ if tolerated in adults aged 80 years and older [14]. I concur with these guidelines [5,16-20]. The Systolic Hypertension in the Elderly Program (SHEP) also showed reduction
*Cardiology Division, Department of Medicine, Westchester Medical Center/New York Medical College, Valhalla, NY, USA; Tel.: +1 9144935311; Fax: +1 9142356274; wsaronow@aol.com

\section{KEYWORDS}

- antihypertensive drugs $\bullet$ blood pressure $\bullet$ hypertension
“Elderly persons have the lowest rates of adequate blood pressure control and the highest incidence of cardiovascular events." 


\section{"Blood pressure is adequately controlled in $36 \%$ of men and $28 \%$ of women between ages $60-79$ years and in 38\% of men and $23 \%$ of women aged 80 years and older.”}

in cardiovascular events in elderly patients including those older than 80 years whose SBP was reduced to between $140-145 \mathrm{mmHg}$ by antihypertensive drug therapy [21].

The 2012 International Society of Nephrology guidelines for treatment of blood pressure in patients with nondialysis-dependent CKD recommended that adults with CKD without diabetes mellitus [22] or with diabetes mellitus [23] with hypertension and albuminuria less than $30 \mathrm{mg}$ per $24 \mathrm{~h}$ should have their blood pressure lowered to $\leq 140 / \leq 90 \mathrm{mmHg}$ with a class I $\mathrm{B}$ indication. If albuminuria greater than $30 \mathrm{mg}$ per $24 \mathrm{~h}$ is present, lowering of the blood pressure to $\leq 130 / \leq 80 \mathrm{mmHg}$ has a class II D indication $[22,23]$ which I would not follow.

The American Diabetes Society 2013 guidelines recommended that diabetics with hypertension should have their SBP lowered to less than $140 \mathrm{mmHg}$ [24]. A SBP of less than $130 \mathrm{mmHg}$ may be considered in younger patients with long life expectancy if achieved with few drugs and without side effects [24].

The European Society of Hypertension/ European Society of Cardiology 2013 guidelines recommended lowering the SBP to less than $140 \mathrm{mmHg}$ in patients at low to moderate cardiovascular risk, diabetics, prior stroke or transient ischemic attack, coronary heart disease and CKD [25]. In older patients younger than 80 years with a SBP $\geq 60 \mathrm{mmHg}$, the SBP should be reduced to $140-150 \mathrm{mmHg}$ with consideration of a SBP less than $140 \mathrm{mmHg}$. In patients older than 80 years with a SBP $\geq 160 \mathrm{mmHg}$, the SBP should be reduced to $140-150 \mathrm{mmHg}$ provided they are in good physical and mental conditions [25].

The 2014 guidelines report from the Eighth Joint National Committee (JNC 8) on management of high blood pressure in adults recommended lowering the blood pressure to less than $140 / 90 \mathrm{mmHg}$ in patients younger than 60 years and in patients aged 60 years and older with diabetes mellitus or CKD [26]. These guidelines recommended lowering the blood pressure to less than $150 / 90 \mathrm{mmHg}$ in patients aged 60 years and older without diabetes mellitus or CKD [26. I agree with their diastolic blood pressure goal but disagree with their SBP goal in patients aged 60 years and older as does a minority report from JNC 8 [27], and the American College of Cardiology Foundation/American Heart Association 2011 expert consensus document on hypertension in the elderly which recommended that the SBP goal in patients younger than 80 years with hypertension without CKD or diabetes mellitus should be less than $140 \mathrm{mmHg}[14,27]$. Data from recently published studies also favor a SBP goal less than $140 \mathrm{mmHg}$ in patients aged 60 years and older [28,29].

Elderly persons have the lowest rates of adequate blood pressure control and the highest incidence of cardiovascular events. Blood pressure is adequately controlled in $36 \%$ of men and $28 \%$ of women between ages $60-79$ years and in 38\% of men and $23 \%$ of women aged 80 years and older [30]. I am very concerned that the higher SBP goal in older persons recommended by JNC 8 will lead to a higher incidence of cardiovascular events and mortality associated with poor control of hypertension.

The European Society of Hypertension position paper summarizes current evidence, unmet needs and practical recommendations on use of renal sympathetic denervation to treat resistant hypertension in hypertension excellence centers [31]. However, the Symplicity HTN-3 study showed in 535 patients with resistant hypertension randomized to renal artery sympathetic denervation using a Medtronic Symplicity catheter system or to a sham control group that renal artery sympathetic denervation was not better than a sham-control arm in reducing office SBP at 6 months or 24-h ambulatory SBP at 6 months [32]. This study also showed at 6 months no benefit of renal artery sympathetic denervation on reduction in ambulatory SBP in either the 24-h or day and night periods compared with the sham procedure [33].

The 2014 American Society of Hypertension/ International Society of Hypertension guidelines recommended reducing the blood pressure to less than $140 / 90 \mathrm{mmHg}$ in patients younger than 80 years of age [34]. These guidelines recommended lowering the blood pressure to less than $150 / 90 \mathrm{mmHg}$ in patients aged 80 years and older [34].

Financial \& competing interests disclosure The author has no relevant affliations or financial involvements with any organization or entity with a financial interest in or financial conflict with the subject matter or materials discussed in the manuscript. This includes employment, consultancies, honoraria, stock ownership or options, expert testimony, grants or patents received or pending or royalties.

No writing assistance was utilized in the production of this manuscript. 


\section{References}

1 Chobanian AV, Bakris GL, Black HR et al. TheSeventh Report of the Joint National Committee on Prevention, Detection,Evaluation, and Treatment of High Blood Pressure. The JNC 7 Report. JAMA 289, 2560-2572 (2003).

2 American Diabetes Association. Standards of medical care for patients with diabetes mellitus. Diabetes Care 26(Suppl. 1) S33-S50 (2003).

3 National Kidney Foundation. K/DOQI clinical practice guidelines for chronic kidney disease: evaluation, classification, and stratification. Am. J. Kidney Dis. 39 (Suppl. 1) S1-S266 (2002).

4 Rosendorff C, Black HR, Cannon CP et al. Treatment of hypertension in the prevention and management of ischemic heart disease. A scientific statement from the American Heart Association Council for High Blood Pressure Research and the Councils on Clinical Cardiology and Epidemiology and Prevention. Circulation 115, 2761-2788 (2007).

5 Aronow WS. Hypertension guidelines. Hypertension 58, 347-348 (2011).

6 Bangalore S, Qin J, Sloan S, Murphy SA, Cannon CP. PROVE IT-TIMI investigators. What is the optimal blood pressure in patients after acute coronary syndromes? Relationship of blood pressure and cardiovascular events in the Pravastatin or Atorvastatin Evaluation and Infection Therapy-Thrombolysis in Myocardial Infarction (PROVE IT-TIMI) 22 trial. Circulation 122, 2142-2151 (2010).

7 Cooper-DeHoff RM, Gong Y, Handberg EM et al. Tight blood pressure control and cardiovascular outcomes among hypertensive patients with diabetes and coronary artery disease. JAMA 304, 61-68 (2010).

8 The ACCORD Study Group. Effects of intensive blood-pressure control in Type 2 diabetes mellitus. N. Engl. J. Med. 362, 1575-1585 (2010).

9 Redon J, Mancia G, Sleight P et al. Safety and efficacy of low blood pressures among patients with diabetes. Subgroup analyses from the ONTARGET (ONgoing Telmisartan Alone and in combination with Ramipril Global Endpoint Trial). J. Am. Coll. Cardiol. 59, 74-83 (2012).

10 Mancia G, Schumacher H, Redon J et al. Blood pressure targets recommended by guidelines and incidence of cardiovascular and renal events in the Ongoing Telmisartan Alone and in Combination
With Ramipril Global Endpoint Trial (ONTARGET). Circulation 124, 1727-1736 (2011).

11 Upadhyay A, Earley A, Haynes SM, Uhlig K. Systematic review: blood pressure target in chronic kidney disease and proteinuria as an effect modifier. Ann. Intern. Med. 154, 541-548 (2011)

12 Banach M, Bhatia V, Feller MA et al. Relation of baseline systolic blood pressure and long-term outcomes in ambulatory patients with chronic mild to moderate heart failure. Am. J. Cardiol. 107, 1208-1214 (2011).

13 Ovbiagele B, Diener H-C, Yusuf S et al. Level of systolic blood pressure within the normal range and risk of recurrent stroke. JAMA 306, 2137-2144 (2011).

14 Aronow WS, Fleg JL, Pepine CJ et al. ACCF/ AHA 2011 expert consensus document on hypertension in the elderly: a report of the American College of Cardiology Foundation Task Force on Clinical Expert Consensus Documents. Developed in collaboration with the American Academy of Neurology, American Geriatrics Society, American Society for Preventive Cardiology, American Society of Hypertension, American Society of Nephrology, Association of Black Cardiologists, and European Society of Hypertension. J. Am. Coll. Cardiol. 57, 2037-2114 (2011).

15 Beckett NS, Peters R, Fletcher AE et al. Treatment of hypertension in patients 80 years of age or older. N. Engl. J. Med. 358, 1887-1898 (2008).

16 Banach M, Aronow WS. Should we have any doubts about hypertension therapy in elderly patients? ACCF/AHA 2011 expert consensus document on hypertension in the elderly. Pol. Arch. Med. Wewn. 121, 253-258 (2011).

17 Aronow WS, Banach M. Ten most important things to learn from the ACCF/AHA 2011 expert consensus document on hypertension in the elderly. Blood Press. 21, 3-5 (2012).

18 Aronow WS. What should the optimal blood pressure goal be in patients with diabetes mellitus or chronic kidney disease? Arch. Med. Sci. 8, 399-402 (2012).

19 Banach M, Aronow WS. Blood pressure j-curve: current concepts. Curr. Hypertens. Rep. 14, 556-566 (2012).

20 Banach M, Aronow WS. Hypertension therapy in the older adults-do we know the answers to all the questions? The status after publication of the ACCFAHA expert consensus document on hypertension in the elderly. J. Hum. Hypertens. 26, 641-643 (2012).
21 SHEP Cooperative Research Group. Prevention of stroke by antihypertensive drug treatment in older persons with isolated systolic hypertension. Final results of the Systolic Hypertension in the Elderly Program (SHEP). JAMA 265, 3255-3264 (1991).

22 KDIGO Clinical Practice Guideline for the Management of Blood Pressure in Chronic Kidney Disease. Chapter 3. Blood pressure management in CKD ND patients without diabetes mellitus. Kidney Int. Suppl. 2, 357-362 (2012).

23 KDIGO Clinical Practice Guideline for the Management of Blood Pressure in Chronic Kidney Disease. Chapter 4. Blood pressure management in CKD ND patients with diabetes mellitus. Kidney Int. Suppl. 2, 363-369 (2012).

24 American Diabetes Association. Position statement. Standards of Medical Care in Diabetes 2013. Diabetes Care 36(Suppl. 1), S11-S66 (2013).

25 Mancia G, Fagard R, Narkiewicz K et al. 2013 ESH/ESC guidelines for the management of arterial hypertension: the task force for the management of arterial hypertension of the European Society of Hypertension (ESH) and of the European Society of Cardiology (ESC). Eur. Heart. J. 34, 2159-2219 (2013).

26 James PA, Oparil S, Carter BL et al. 2014 evidence-based guideline for the management of high blood pressure in adults. Report from the panel members appointed to the eighth Joint National Committee (JNC 8). JAMA 311, 507-520 (2014).

27 Wright JT Jr, Fine LJ, Lackland DT, Ogedegbe G, Dennison-Himmelfarb CR. Evidence supporting a systolic blood pressure goal of less than $150 \mathrm{mmHg}$ in patients aged 60 years or older: the minority view. Ann. Intern. Med. 160, 499-503 (2014).

28 Banach M, Bromfield S, Howard G et al. Association of systolic blood pressure levels with cardiovascular events and all-cause mortality among older adults taking antihypertensive medication. Int. J. Cardiol. 176, 219-226 (2014)

29 Bangalore S, Gong Y, Cooper-DeHoff RM, Pepine CJ, Messerli FH. 2014 Eighth Joint National Committee panel recommendation for blood pressure targets revisited: results from the INVEST study. J. Am. Coll. Cardiol. 64, 784-793 (2014).

30 Lloyd-Jones DM, Evans JC, Levy D. Hypertension in adults across the age spectrum: current outcomes and control in the community. JAMA 294, 466-472 (2005). 


\section{EDITORIAL Aronow}

31 Schmieder RE, Redon J, Grassi G et al. ESH position paper: renal denervation - an interventional therapy of resistant hypertension. J. Hypertens. 30, 837-841 (2012).

32 Bhatt DL, Kandzari DE, O'Neill WW et al. A controlled trial of renal denervation for resistant hypertension. N. Engl. J. Med. 370, 393-401 (2014).

33 Bakris GL, Townsend RR, Liu M et al. Impact of renal denervation on 24-hour ambulatory blood pressure: results from SYMPLICITY HTN-3. J. Am. Coll. Cardiol. 64, 1071-1078 (2014).
34 Weber MA, Schiffrin EL, White WB et al. Clinical practice guidelines for the management of hypertension in the community. A statement by the American Society of Hypertension and the International Society of Hypertension. J. Hypertens. 32, 3-15 (2014). 